\title{
Treatment of a Chronic Wound - a case report of a Patient treated at The Centre FOR HYPERBARIC OXYGEN AND TREATMENT OF WOUNDS IN BYDGOSZCZ
}

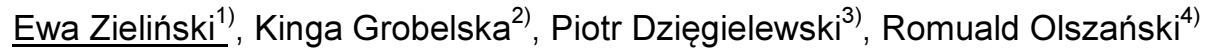 \\ 1) Department of Emergency Medicine and Disaster Collegium Medicum Ludwika Rydygiera in Bydgoszcz, Nicolaus Copernicus University, Toruń, Poland \\ 2) The Centre for Hyperbaric Oxygen and Wound Treatment in Bydgoszcz, Poland \\ 3) 10 Military Clinical Hospital with a Polyclinic. Independent Public Health Care Center Bydgoszcz, Poland \\ 4) Maritime \& Hyperbaric Medicine Department Military Institute of Medicine, Gdynia, Poland
}

\section{ABSTRACT}

This paper presents a case report of a patient with a diagnosed complication of a sternum wound which was treated using hyperbaric oxygen, emphasizing the truism of the benefits of combined surgical therapy, antibiotic therapy and oxybarotherapy.

Keywords: oxybarotherapy, slow-healing wound, sternum.

\section{ARTICLE INFO}

PolHypRes 2018 Vol. 63 Issue 2 pp. 39 - 44

ISSN: 1734-7009 elSSN: 2084-0535

DOI: $10.2478 /$ phr-2018-0011

Pages: 6, figures: 2, tables: 0

page www of the periodical: www.phr.net.pl

Publisher

Polish Hyperbaric Medicine and Technology Society
Casuistic (case description) article

Submission date: 11.02.2018 r.

Acceptance for print: 23.04.2018 r. 


\section{INTRODUCTION}

Accelerating the healing of chronic, difficult to heal wounds reduces the risk of complications, increases the possibility of treatment and rehabilitation, and improves the quality of life of patients. Despite the use of various therapeutic methods, effective treatment of chronic wounds is still a challenge. One of the therapeutic methods in this area, requiring further research, is hyperbaric oxygen therapy. It should be emphasized that the treatment of chronic wounds is a significant diagnostic, scientific and economic problem [1].

The truism of the benefits of the use of oxybarotherapy concerns not just strictly medical aspects, but also economic and social aspects. In attempting to analyse the effectiveness of this method of treatment one should also focus on additional benefits such as: reduction of social costs resulting from disability and, above all, improvement of the patient's quality of life.

This paper presents the therapeutic process of a patient with a diagnosed complication of a sternum wound treated with the aid of hyperbaric oxygen. The truism of the benefits of combined therapy: surgical treatment, antibiotic therapy and oxybarotherapy.

\section{Chronic WOUnD}

Chronic wounds are an important health problem affecting many people around the world. In developing countries, it affects $1-2 \%$ of the population $[2,7]$. The approximate number of patients suffering from chronic wounds in Poland is about 500,000. people [8].

Chronic wounds are wounds that are not subject to physiological treatment. They remain "trapped" by an uncoordinated and self-sustaining phase of inflammation that impairs the correct renewal of anatomical and functional integrity [2]. A chronic wound can also be defined as skin damage lasting longer than 6 weeks or a frequently renewing lesion [3]. It is difficult to give one universal definition of a chronic wound, in the literature on the subject, different periods of wound healing (from 4 weeks to several months), usually an extension of the wound healing period above 6-8 weeks, are considered as a basis for diagnosis of a chronic wound $[4,5]$.

As results from the analysis of the literature, clinical problems related to complications in the form of a sternal divergence after cardiac surgery in which a middle sternotomy was performed constitute from 0.5 to $5 \%$ of procedures [6].

The following is a case of a patient being treated at The Centre for Hyperbaric Oxygen and Treatment of Wounds in Bydgoszcz.

\section{CASE DESCRIPTION}

Patient, aged 67, directed to The Centre for Hyperbaric Oxygen and Treatment of Wounds due to a reluctant wound of the sternotomy bridge. The patient presented with the following conditions: heart failure, paroxysmal atrial fibrillation, MS. On December 14, 2015, the patient underwent cardiac surgery. Procedure performed: aortic valve implantation and supra-coronary prosthesis.

During surgery due to profuse bleeding, the decision was made to postpone closure of the chest. On
December 15, 2016, after stabilization of the general condition of the patient, a decision was made to close the chest. The course of the procedure was without complications. In the postoperative period, the patient was agitated in terms of the psychomotor behaviour. Subsequently the fastening wires responsible for securing the sternum broke and a significant leak of serous content from the wound was noted. Antibiotic therapy was initiated and the lower part of the wound was opened in order to apply a VAC dressing. On December 30, 2016, the chest wound was again closed. After a few days, the sternum became unstable and dispersed. The chest wound was reopened and necrotic bone fragments removed.

The VAC dressing was re-applied and again antibiotic therapy was included. In the performed swab the following bacterial cultures were noted: Corynebacterium species, Staphylococcus species, Staphylococus epidermidis. On April 7, 2016, due to difficulties in healing the sternum wound, the patient was referred to The Center for Hyperbaric Oxygen and Treatment of Wounds in Bydgoszcz in order to include hyperbaric oxygen therapy in the therapeutic process. Upon arrival at the center it was found that the patient had a wound measuring $22 \mathrm{~cm} / 5 \mathrm{~cm}$, depth $6 \mathrm{~cm}$. Topical fibrin and necrosis occurred along with inflammation with a large amount of purulent exudate coming from the wound. In the past, moreover, the patient had suffered from hypertension and due to severe pain (NRS 6-8 points), the patient has been taking painkillers: Tramal, Pyralgina, Paracetamol. 


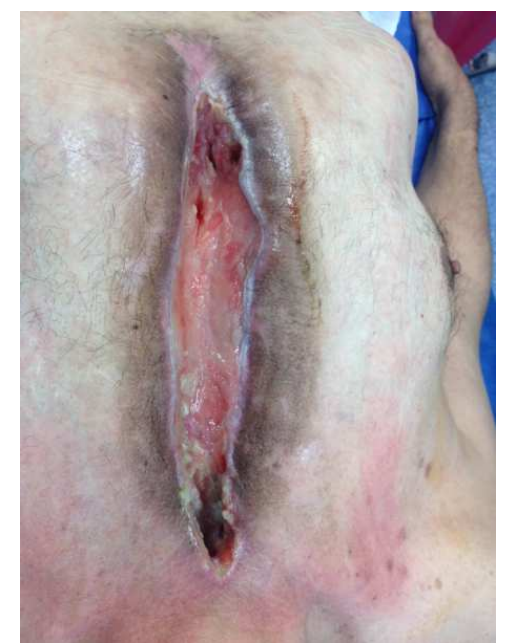

Fig. 1 Image of the local condition at the admission to The Centre for Hyperbaric Oxygen and Wound Treatment. Source: own materials.

The patient was qualified for 30 hyperbaric oxygen therapy sessions. Measurement of oxygen tension in the skin (TcPO2) in the first week of therapy before the session in the hyperbaric chamber was $28 \mathrm{mmHg}$, after therapy $52 \mathrm{~mm}$ mercury.

No hyperbaric oxygen therapy complications were observed. Due to a significant amount of exudate from the wound area, ciprofloxacin was included, followed by cloxacillin. During the entire stay, the patient remained under the constant supervision of the attending and triage doctor for treatment with oxybarotherapy.
During his stay at The Center for Hyperbaric Oxygen and Wound Treatment, the patient was supplied with hyperbaric oxygen therapy with the use of highly specialised dressings. After 29 out of 30 sessions of hyperbaric oxygen therapy, on May 20, 2016, oxybarotherapies were completed. Of course, the patient was still under the constant supervision of the attending physician. An analgesic effect was obtained (3 points on the NSR scale) as well as an improvement of the local condition of the chronic wound. There were also no signs of inflammation.

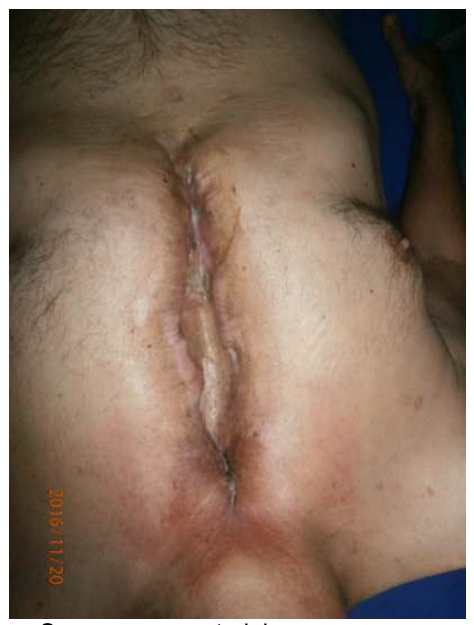

Fig. 2 Image of the local state after the end of hyperbarotherapy. Source: own materials.

Final results:

- no signs of skin inflammation,

- healing wounds in the chronic area of the sternum,

- significant improvement of the local condition without signs of infection,

- reduction of pain (at the end of 3-point therapy on the NRS scale).

\section{Conclusions}

In conclusion, hyperbaric oxygen therapy is effective in the treatment of chronic wounds in adult patients. Hyperbaric oxygenotherapy by directly inhibiting the growth of anaerobic bacteria and stimulating the bactericidal properties of white blood cells in the fight against aerobic bacteria is an important supportive element in the treatment of infection. The inclusion of hyperbaric oxygen therapy in the therapeutic process certainly reduces the time of therapy and in many cases allows to protect the patient against complications in the form of disability. Hyperbaric therapy is expensive, however, it shortens the time of hospitalization and the use of expensive antibiotics, which in the final analysis may turn out to be beneficial [9].

It should be emphasized that hyperbaric oxygen therapy is a supportive therapy and cannot be an alternative to surgical treatment or antibiotic therapy. The therapeutic experience of the authors allows to pay attention to favorable changes in measured parameters: 
maximum pain intensity, maximum wound size.

The authors are undertaking work on the evaluation of the impact of hyperbaric oxygen treatment on chronic wounds, but they have noticed one more aspect. Namely, it is also important to compare the quality of life of patients with chronic wounds.

\section{REFERENCES}

1. Szewczyk M. T., Jawień A. (ed.) Chronic wound treatment. Wyd. Lekarskie PZWL, Warsaw 2012;

2. Menke N., Ward K., Witten T. et al.: Impaired wound healting. Clin. Dermatol., 2007,25,19-25;

3. Wild T., Rahbarnia A., Kellner M. et al.: Basics in nutrition and wound healting. Nutrition, 2010, 26(9), 862-866;

4. Siddiqui A.R., Bernstein J.M.: Chronic wound infection: facts and controversies. Clin.Dermatol., 2010, 28(5), 519-526

5. Szewczyk M.T., Cwajda J., Cierzniakowska K. et al.: Selected aspects of chronic wound treatment. Przew.Lek., 2005, 5, 54-60;

6. 6.Listewnik M., Kazimierczak A., Mokrzycki K.: Complications of cardiac surgery: sternal dehiscence after median sternotomy. Analysis of 14,171 cases operated on in years 1990-2009; Pom J Life Sci 2015, 61, 4, 383-388;

7. Gottrup F.: A specjalized wound - healing center concept importance of a multidisciplinary department structure and surgical treatment facilities in the treatment of chronic wounds. Am. J Surg., 2004,187, 38S-43S;

8. Krasowski G., Kruk M.: Treatment of bedsores and chronic wounds. Wydawnictwo Lekarskie PZWL, Warsaw 2008;

9. Bryndza M., Filip G., Bartuś K. et al.: Hyperbaric oxygen therapy in treating a poorly healing wound following cardiac surgery in a patient with congenital connective tissue defect - case; Polish Hyperbaric Research, 2017, 4(61), 25-32.

\section{dr Ewa Zieliński}

Katedra Medycyny Ratunkowej i Katastrof Collegium Medicum im. Ludwika Rydygiera w Bydgoszczy,

Uniwersytet Mikołaja Kopernika w Toruniu

ul. M. Curie Skłodowskiej 9, 85-094 Bydgoszcz

ewa.zielinski.bydgoszcz@wp.pl 